\title{
BIM EM PROJETO DE ARQUITETURA PAISAGISTA: ATUAIS OBSTÁCULOS E BENEFÍCIOS.
}

\author{
Bruno Martins ${ }^{(1)}$, António Nazaré Pereira ${ }^{(1)}$, Domingos Lopes ${ }^{(1)}$ \\ (1) Universidade de Trás-os-Montes e Alto Douro, Vila Real
}

\begin{abstract}
Resumo
A crescente utilização de BIM em projeto e construção exige que todos os profissionais ligados a esta atividade incorporem esta técnica, permitindo uma maior integração entre as diferentes áreas de atividade. Os arquitetos paisagistas não são exceção e têm vindo a ser crescentemente solicitados para desenvolver os seus projetos em software BIM. Porém, dado que a Arquitetura Paisagista combina materiais inertes naturais e artificiais com materiais vivos, isto é, vegetação, são necessárias ao arquiteto paisagista ferramentas específicas para as operar nem sempre existentes nas diferentes soluções BIM disponíveis no mercado. Por exemplo, são necessárias ao arquiteto paisagista ferramentas que permitam lidar diretamente com as diferentes formas de plantação, fases de crescimento, sazonalidade da vegetação, dimensionamento do sistema de rega consoante as necessidades hídricas das plantas e trabalhos de manutenção da vegetação após a conclusão da obra. Uma vez que muitos arquitetos paisagistas trabalham já com esta técnica um pouco por todo o mundo, o presente trabalho visa uma reflexão acerca das formas encontradas pelos profissionais, mas também por alunos de arquitetura paisagista, para contornar as dificuldades e desenvolver os seus projetos. Além disso, expõem-se possíveis ferramentas, úteis para a profissão, que alguns programadores podem desenvolver. Espera-se desta forma contribuir para a uma melhor integração da Arquitetura Paisagista no sistema BIM e para que mais arquitetos paisagistas possam para ele migrar.
\end{abstract}

\section{Introdução}

$\mathrm{O}$ advento do Building Information Modelling (BIM) trouxe consigo uma forma integradora de desenvolvimento de projeto em todas as suas fases, desde a conceção, passando pela construção e manutenção até ao fim de vida útil. Desde o tempo dos antigos egípcios, que usavam modelos na forma de desenhos e objetos, à invenção do rato de computador, na década de 1970 , e ao desenvolvimento do BIM nos anos 1990 [1] que a área da Arquitetura, Construção e Engenharia (ACE) tem vindo a sofrer significativos progressos, nomeadamente na área do projeto. $\mathrm{O}$ facto de o BIM possibilitar o trabalho a sete e oito dimensões permitiu também conectar o trabalho 
de diferentes profissionais da área da $\mathrm{ACE}$, os quais poderão agora trabalhar num modelo comum. Os arquitetos paisagistas são chamados também a colaborar.

Este facto reflete-se naturalmente no ensino da arquitetura paisagista e na Universidade de Trásos-Montes e Alto Douro o software BIM foi incluído no currículo de formação. Além disso, os jovens arquitetos paisagistas sentem necessidade de adquirir mais formação nesta área, principalmente aqueles que se deslocam para países onde o seu domínio é compelido [2], [3]. Alunos e profissionais deparam-se também com diversos obstáculos na migração para o BIM, de que é exemplo a carência de ferramentas específicas para o desenvolvimento dos componentes essenciais do projeto de arquitetura paisagista. Isso conduz ao uso de outras tipologias de software, usando-se somente o BIM no final do projeto, como mera forma de apresentação/envio do trabalho final.

O conceito de Landscape Information Modelling (LIM) é, aliás, um esforço para solucionar estas questões [4], [5]. Contudo, se um dos princípios do BIM é facilitar a troca de informação entre os profissionais ligados à AEC, e o valor dessa integração é reconhecida [6], apesar de todas as vantagens do LIM [2], [5] essa opção continua a ditar o seu afastamento dos restantes profissionais da AEC. O processo de construção é um trabalho colaborativo que requer a partilha de informações e comunicação entre os diferentes intervenientes na obra [7], e o sistema utilizado para troca de informação deve ser o mesmo ou, pelo menos, apresentar alta compatibilidade de modo que a informação possa ser acedida na íntegra.

Entre as dificuldades sentidas pelos arquitetos paisagistas que se iniciam no BIM encontram-se as relacionadas com a análise do local, a modelação de terreno e pavimentos associados à sua superfície, o revestimento vegetal, o sistema de rega e a manutenção do espaço após a conclusão da obra. O presente trabalho visa uma reflexão acerca dos obstáculos, mas também das formas encontradas pelos profissionais e alunos para os contornar e assim poderem desenvolver os seus projetos. Esta reflexão surge da experiência dos autores enquanto docentes e profissionais, quer enquanto o exercício da atividade letiva quer no contacto profissional com o BIM, por experiência própria ou em conversas com profissionais de diferentes áreas, e aborda algumas das questões então colocadas (Figura 1). Além disso, sugere-se a criação de ferramentas e a melhoria de outras existentes, úteis para a profissão.

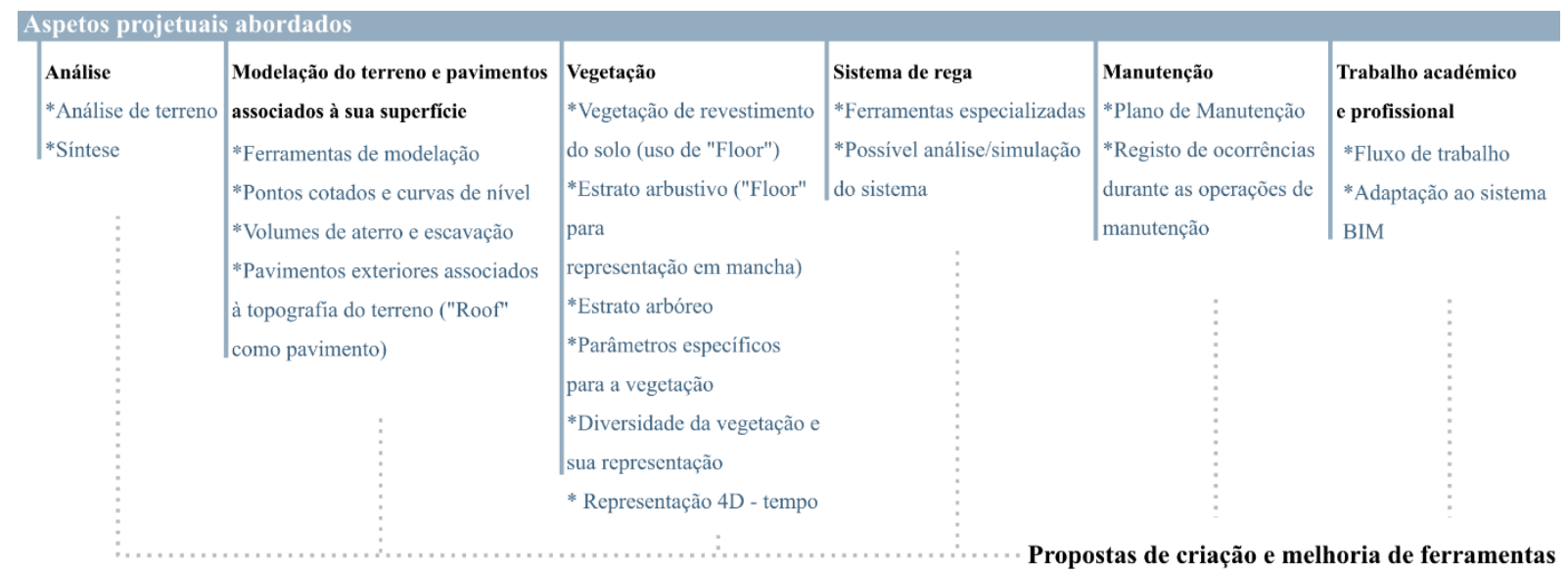

Figura 1: Aspetos projetuais abordados. 


\section{BIM em projeto de arquitetura paisagista: etapas de projeto e ferramentas de trabalho}

\subsection{Análise}

Uma vez que o arquiteto paisagista trabalha com elementos naturais, a análise do local de projeto é imprescindível ao sucesso e viabilidade da proposta. Alguns programas BIM possuem ferramentas de análise úteis à profissão, como por exemplo a orientação solar. Porém existe lacuna de outras ferramentas de análise. Por exemplo, é comum realizarem-se análises aos diversos fatores e, no final, realizar-se uma síntese, por sobreposição das mesmas, de modo a obter os locais com melhor aptidão para determinada função (método proposto por Ian McHarg). Não estando disponíveis estas ferramentas, alunos e profissionais de arquitetura paisagista continuam a executar estas análises noutro software, de que são exemplo os Geographical Information System (GIS) ou o Autocad Civil 3D®, muito úteis nesta etapa do projeto [8]. Em consequência, são introduzidos erros durante a troca e/ou conversão entre diferente software e é despendido tempo a realizar tarefas que é necessário repetir em cada um [7], bem como tarefas de conversão.

Dado o BIM ser um sistema baseado em informação e dado estas análises se basearem na topografia ou outras informações já existentes no próprio sistema, de que é exemplo a localização geográfica, a incorporação de ferramentas de análise, como por exemplo as exposições solares, os declives, o escorrimento superficial de águas pluviais, a hipsometria, bem como a possibilidade de as sintetizar no final, são fatores importantes para atrair mais arquitetos paisagistas e até originar uma interação interessante se estas análises puderem ser visualizadas em 3D. Além disso, é uma questão de integração de todas as fases de projeto/construção no mesmo sistema.

\subsection{Modelação do terreno e pavimentos associados à sua superfície}

O terreno é a base de trabalho do arquiteto paisagista. Projetar o escorrimento de águas, as linhas visuais, em suma, a paisagem a três dimensões, promove um controlo geral mais intuitivo sobre o projeto [7]. Além disso, este entendimento e visualização do local de projeto auxilia o arquiteto paisagista a obter melhores soluções para o local. Os alunos de arquitetura paisagista apreciam particularmente esta ferramenta uma vez que em muito os ajuda a perceber aquilo que estão a conceber e também a terem um melhor sentido de espaço [9], em contraste com a conceção a duas dimensões que requer uma maior capacidade de visualização espacial e experiência. Apesar de os programas BIM possuírem de forma geral uma ferramenta de representação do terreno, as ferramentas de análise descritas anteriormente, e geralmente também a ele associadas, são praticamente inexistentes. Tomando como exemplo o Autodesk Revit 2019®, uma vez que é um dos mais difundidos e utilizados, este disponibiliza ferramentas de análise associadas aos edifícios, como por exemplo análise térmica ou de sistemas MEP (Mechanical, Electrical and Plumbing), porém carece de ferramentas de análise de terreno. A Autodesk ${ }^{\circledR}$ pretende articular as ferramentas com o Autocad Civil 3D® [2], o que resolveria esta situação.

Um outro obstáculo com que alunos e profissionais de arquitetura paisagista se deparam é a dificuldade em modelar o terreno por falta de ferramentas apropriadas para o efeito. Existem programas BIM que desenvolveram mais esta área, como por exemplo o Vectorworks ${ }^{\circledR}$ ou o Allplan ${ }^{\circledR}$, enquanto outros, como o já citado Revit $2019 \AA$, se resumem a ferramentas mais "básicas". Uma situação muitas vezes apontada por profissionais e alunos prende-se com a 
modelação de terreno que tem de ser exclusivamente elaborada por pontos cotados, ao invés do conjunto composto por curvas de nível e pontos cotados com que os arquitetos paisagistas geralmente trabalham. Há muitos que recorrem a software externo, mas isso prejudica muito o fluxo de trabalho. No decorrer das aulas, quando os alunos se deparam com esta contrariedade, dificilmente conseguem desenvolver o restante projeto sem serem profundamente auxiliados. Além disso, e já em contexto profissional, optar por trabalhar num software BIM diferente das restantes especialidades inviabiliza o trabalho, uma vez que a compatibilidade entre software é mínima e os problemas que daí advém significativos.

Uma outra ferramenta muito valorizada pelos alunos é o cálculo de volumes de aterro e de escavação que, contrariamente a outras ferramentas relacionadas com o terreno já mencionadas e em falta, os programas BIM contemplam de modo geral. Além de muito facilitar o trabalho, esta ferramenta permite realizar ajustes na modelação de terreno de uma forma interativa e com precisão, possibilitando obter a melhor solução de aterro/escavação para o local [7]. Este instrumento é também vantajoso em ambiente profissional, dada a relativa rapidez com que se testam as diferentes soluções e dado o escasso tempo dos gabinetes para elaborar projeto, o que lhes permite estudar mais opções e consecutivamente melhorar o resultado final.

Os pavimentos exteriores são outro dos obstáculos encontrados, nomeadamente aqueles que "acompanham" a topografia do terreno, que muito contribuem para o desinteresse dos alunos e profissionais de arquitetura paisagista por este tipo de software. De facto, os programas BIM estão sobretudo preparados para desenvolver pavimentos interiores, mas não para desenvolver pavimentos exteriores como percursos deambulantes ao longo da topografia do terreno. A solução encontrada passa muitas vezes por usar outros elementos. Por exemplo, no Revit 2019®, em vez dos tradicionais Floor podem usar-se Roofs (Figura 2), visto os telhados serem mais flexíveis ao assumir diferentes formas 3D. Assim sendo, por meio da divisão da superfície de terreno de modo a isolar aquilo que será o futuro caminho, exportando para formato CAD, importando novamente como uma mass e transformando finalmente em Roof, consegue-se que acompanhem o terreno sem descurar as vantagens como a estratificação/pormenorização dos pavimentos necessária para a elaboração do projeto de execução. Porém e como se verifica, é necessário todo um processo consideravelmente extenso e complexo, situação esta que poderia ser facilmente resolvida com a inserção de uma ferramenta própria para o efeito. Além disso, um utilizador, externo à arquitetura paisagista, que se depare com esta construção de projeto poderá ficar baralhado, mas, de facto, a alternativa é escassa ou inexistente. Será por isso vantajosa a existência de uma ferramenta que fixe os pavimentos tradicionais de arquitetura à topografia do terreno e que permita a micro-modelação de cotas destinadas ao escorrimento de águas pluviais [7].

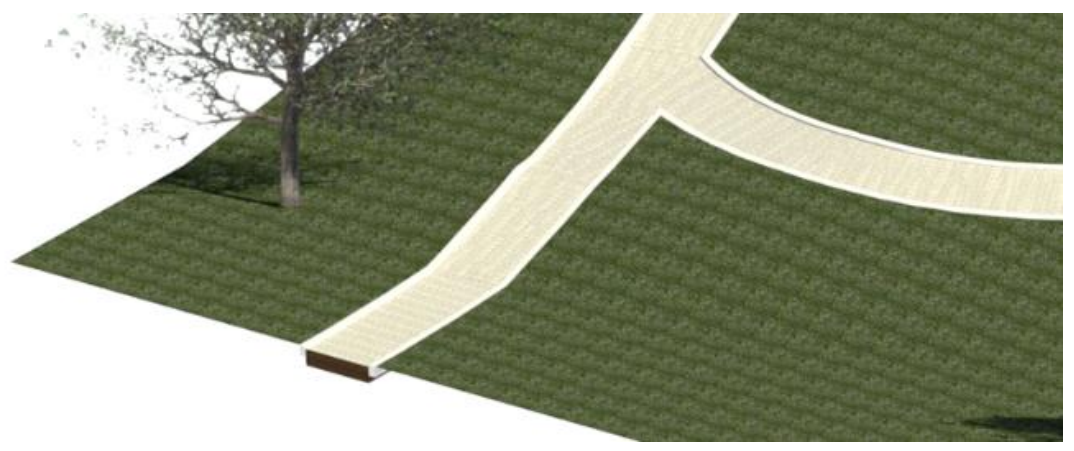

Figura 2: Utilização de Roof como caminho. 


\subsection{Vegetação}

No projeto de arquitetura paisagista a vegetação é agrupada e representada em três grandes grupos: vegetação de revestimento do solo, estrato arbustivo e estrato arbóreo. Uma vez que se tratam de diferentes camadas que podem coexistir é importante a sua separação em diferentes planos técnicos.

Posto isto, a vegetação, nomeadamente a de cobertura do solo, herbácea ou outros revestimentos do solo inertes, são criados geralmente pelos arquitetos paisagistas através da ferramenta para criar pavimentos arquiteturais. Embora esta situação esteja já assimilada por quem já trabalha em BIM, quando esta questão é apresentada pela primeira vez, os alunos reagem com alguma estranheza apesar de, após se lhes apresentar os motivos, rapidamente compreenderem. Num pavimento arquitetural é possível configurar a espessura (height), trabalhar com diversas camadas de materiais (layers) e calcular a área, ou seja, parte das caraterísticas que se esperam encontrar num revestimento vegetal. Por outro lado, utilizando este método, um dos parâmetros que nem sempre se adequa é a representação da camada superficial, ou seja, a da vegetação, em três dimensões e em render. Minimizando o problema, o Vectorworks ${ }^{\circledR}$ já permite realizar, por exemplo, relvados em 3D, mas o Revit 2019® e outros não o permitem, pelo menos diretamente. Porém, excetuando os relvados, a inserção de outro tipo de vegetação de revestimento do solo não está de todo contemplada, pelo que, inserir este tipo de vegetação de pequena dimensão à unidade, conforme o BIM o prevê na sua generalidade, é impensável devido ao trabalho que implicaria.

Quando se trata do estrato arbustivo, o arquiteto paisagista por vezes representa-o por elementos individuais, outras vezes "em mancha", isto é, áreas arbustivas. É também comum encontrar situações onde ambas as formas de representação coexistem. Na representação por elemento a inserção de vegetação é intuitiva e direta. Porém, não existe uma ferramenta direta para inserção por mancha, quer de uma única espécie, quer de composições de plantas, pelo que, embora possível, requer maiores capacidades de operação em geral.

Uma das soluções mais recorrentes passa também por usar os pavimentos arquiteturais, criando uma tipologia/família de pavimento para cada espécie e/ou composição vegetal (Figura 3). Assim, quer para cada espécie, quer para cada mistura, é necessário criar um novo material que corresponda às plantas/composições utilizadas. Apesar de este método alternativo suplantar certas dificuldades de que é exemplo a possibilidade de usar a informação contida na base de dados, a sua grande desvantagem ocorre na representação tridimensional, visto essa "vegetação" não surgir em três dimensões, mas apenas como textura inerente ao pavimento. É ainda possível atribuir cota à camada superficial correspondente à espécie vegetal e assim, numa tentativa de superar esta questão, conseguir visualizar e analisar a composição de volumetrias dos diferentes arbustos. Contudo e apesar de isso poder ser útil para o projetista, apresenta uma aparência de "degraus" quando visualizado, o que não é satisfatório para apresentações ao cliente, ou outras que se preveem mais cuidadas. Dada a importância que esta ferramenta tem para o trabalho do arquiteto paisagista, é vantajosa a criação de uma ferramenta que possibilite a introdução automática de conjuntos de vegetação através de parâmetros como densidade, espaçamento e proporção entre espécies, entre outros, que alguns programas já possuem. 


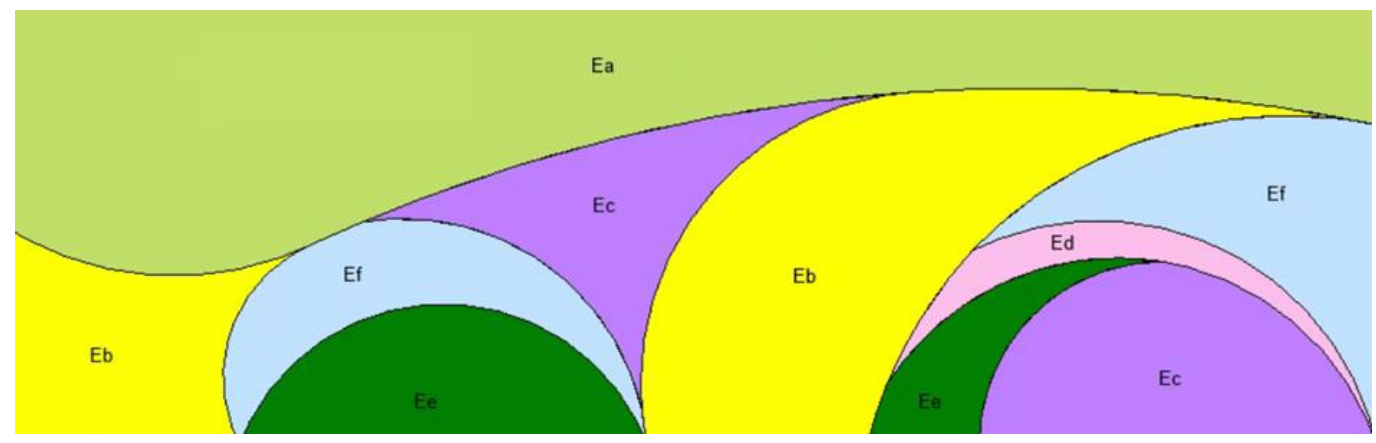

Figura 3: Utilização de Floor / pavimentos para realizar composição arbustiva.

Por outro lado, os programas BIM, de forma geral, representam de forma fácil e intuitiva o estrato das árvores, pelo que não se verificam dificuldades de maior neste caso. Relativamente às árvores, os "smart symbols" com que as árvores são representadas e que automaticamente variam conforme a situação de representação (2D, 3D e render) [3] são um aspeto também muito valorizado pelos alunos, dado evitarem tarefas repetitivas. Notar que seria interessante que na base de dados pudessem ser introduzidos campos específicos para preenchimento de informações técnicas da vegetação, como o nome comum, o nome científico, o perímetro à altura do peito, fuste, etc., bem como outros relativos à sua manutenção, para que no final se pudesse também obter de forma automática o respetivo plano de manutenção. Ressalva-se que se fala na generalidade, uma vez que existem exceções, como é o caso do Vectorworks ${ }^{\circledR}$ que já contempla, se não todas, pelo menos algumas destas questões, e o Revit 2019® no qual parte destas operações são possíveis, embora que não diretamente.

Uma outra questão prende-se com a representação 3D da árvore/arbusto, quando a mesma é baseada numa fotografia, não sendo, portanto, utilizado um verdadeiro objeto 3D. É comum nesta situação a fotografia da planta apresentada ser sempre a mesma cada vez que se usa determinado exemplar. Porém, visto que a vegetação no mundo real tem crescimento e comportamento diferente, sempre que se pretende a representação de vários exemplares da mesma espécie em conjunto a sensação transmitida é a de que foi feito "copy and paste". Isto seria resolvido se fosse possível variar essa imagem. Além disso esta ferramenta poderia ter dupla funcionalidade, posto que existem espécies para as quais é possível optar por diferentes podas de formação e respetiva manutenção. Por exemplo, pode pretender-se ser uni- ou multicaule, pelo que se poderia selecionar também este tipo de parâmetros.

Destacam-se ainda as questões da sazonalidade da vegetação e as diferentes formas que a vegetação propicia ao espaço durante o seu crescimento [5], ambas já consideradas por alguns programas. Dado os programas BIM contemplarem a 4D-tempo [3], salienta-se a importância destas funcionalidades não serem esquecidas. Além disso, quando este critério do crescimento é considerado, este não deverá funcionar isolado no BIM, dado que também no mundo real o crescimento da vegetação reage e interage com o ambiente envolvente [5]. O crescimento vegetal é diferente consoante a espécie, existindo espécies de crescimento mais rápido e espécies de crescimento lento. Aqui reside uma outra oportunidade para usar as ferramentas e informação já presentes no BIM de forma útil para a arquitetura paisagista, de forma que segundo as previsões de crescimento das diferentes espécies, o software possa apresentar a projeção da forma do espaço verde após um intervalo de tempo a definir pelo utilizador.

Uma vez que os programas BIM possuem na generalidade informações sobre a posição geográfica e consequente clima e solo, é também importante cruzar esta informação com a 
vegetação de forma ao software aconselhar o arquiteto paisagista, ajudando assim o projetista a escolher a planta certa para o local certo [3], [5].

\subsection{Sistema de rega}

Enquanto certos software BIM, como o Vectorworks ${ }^{\circledR}$, se encontram melhor preparados para desenhar o sistema de rega, outros como o Revit $2019 \AA$, não o contemplam, pelo menos diretamente. Contudo, este último contempla sistema de incêndio e canalização ( "plumbing"), o que talvez permita uma adaptação.

Dada a complexidade que um sistema de rega pode atingir, o uso de BIM é sem dúvida uma enorme vantagem, uma vez que pode orientar e alertar o projetista para as mais diversas situações e auxiliar também a posteriori na manutenção do mesmo. Os aspersores, electroválvulas e outros acessórios podem ser disponibilizados pelos fabricantes com as devidas configurações, fornecendo assim realismo à simulação. Aliás, este é o método já utilizado pelo software BIM em geral para o mobiliário, iluminação, entre outros. Além disso e visto que o BIM contempla sistemas MEP em geral, bem como as respetivas análises já anteriormente mencionadas, seria uma questão de acrescentar também a análise do sistema de rega, que em muito interessa a todos os profissionais que trabalham em espaços verdes, desde os pequenos jardins residenciais aos grandes parques urbanos.

Porém, neste caso da irrigação e à falta de alternativa, para muitos profissionais a solução passa por usar software auxiliar ou plugins dedicados a esta questão [3], o que propicia um aumento significativo de gastos com o software ao gabinete de arquitetura paisagista, bem como instiga os profissionais que se dedicam apenas a esta especialidade a afastarem-se do BIM.

\subsection{Manutenção}

O sistema BIM está preparado para trabalho pelo menos a 7D, havendo também quem considere o trabalho a 8D se incluirmos a segurança [10], [11]. Nestas dimensões inclui-se também a manutenção. Desde a sua formação, que os arquitetos paisagistas aprendem a desenvolver planos de manutenção. Nesta área verifica-se uma enorme vantagem dos programas BIM face aos restantes programas, mas esta vantagem pode ser ampliada se o software BIM estiver melhor preparado para o projeto de vegetação. Por exemplo, as ferramentas anteriormente propostas relativamente à vegetação e sistema de rega, poderão ter dupla funcionalidade, informando sobre necessidades de rega, podas, adubação, etc., aquando da criação do plano de manutenção. Além disso, também no modelo BIM se poderiam introduzir informações sobre manutenção, como por exemplo datas de ocorrência de problemas/tratamentos fitossanitários ou outras operações, uma base de dados que permitisse gerir o espaço com base no projeto original. Sublinha-se que no caso da arquitetura paisagista, a manutenção é de extrema importância, uma vez que uma incorreta manutenção poderá ditar uma forma do espaço totalmente diferente daquela pensada pelo projetista.

\subsection{Trabalho académico e profissional}

Um dos principais obstáculos identificados pelos estudantes e profissionais de arquitetura paisagista à migração para o BIM é o fluxo de trabalho imposto por este tipo de software. Além disso, quando os estudantes contactam pela primeira vez com o Revit $2019 \AA$ as dificuldades de operação são notórias, nomeadamente a dificuldade em modelar o terreno [12], embora se possam enumerar muitas outras. O ArchiCAD® apresenta semelhantes problemas e, embora $\mathrm{o}$ 
Vectorworks ${ }^{\circledR}$ e o Allplan ${ }^{\circledR}$ se encontrem melhor preparados para a arquitetura paisagista, não se integram bem com os restantes [3], [12].

A variedade de profissionais intervenientes na AEC levou ao desenvolvimento de inúmeras ferramentas. Neste contexto, a existência de ferramentas flexíveis poderá ser uma solução, cada profissional programando e adaptando ferramentas às suas necessidades específicas. Para preparar os alunos para esta realidade, é, porém, necessário que o ensino contemple programação básica e que a programação de ferramentas seja ensinada [2]. Fala-se, por exemplo, da programação visual oferecida pelo Dynamo®, por sua vez disponibilizado com o Autodesk Revit 2019®. É também importante que esse conhecimento lhes seja transmitido num contexto real de trabalho ou de forma a poderem usar as ferramentas desde logo para os seus trabalhos académicos [9], de forma a assim assimilarem essa informação.

Uma outra contrariedade notada nos alunos de arquitetura paisagista é a dificuldade inicial em compreender e operar o BIM. Inicialmente, quando lhes são apresentados os conceitos teóricos do BIM e as ferramentas que o software possui (como o trabalho em 3D, criação automática da superfície de terreno, cortes, secções e alçados automáticos, entre outros) os alunos ficam maravilhados [9]. Porém, quando começam a operar o software e se deparam com o facto de até uma pequena imprecisão poder pôr em causa todo o trabalho, os alunos desanimam e procuram muitas vezes aprender como resolver determinadas situações de cor [9].

Esta vicissitude propicia que os alunos optem por não usar o BIM nos seus trabalhos académicos, optando por software mais simples de operar, mesmo que tenham de utilizar até vários para alcançar o mesmo resultado. Os questionários desenvolvidos por Poerschke et al. [13] corroboram esta ideia, uma vez que os alunos afirmaram frequentemente preferirem ganhar mais experiência a operar o BIM, antes de o usarem num trabalho de projeto.

É importante, porém que os alunos adquiriram experiência durante a sua formação académica para que, quando ingressarem no mercado de trabalho possam contribuir e até liderar equipas de projeto integrado [6]. Além disso, se o aluno ou o profissional estiver preocupado com as questões de interoperabilidade, irá descurar a reflexão e análise crítica do modelo, bem como os resultados das diferentes simulações e alternativas de design [13].

Além da introdução de ferramentas necessárias à arquitetura paisagista, complexas uma vez que os arquitetos paisagistas usam ferramentas de várias áreas disciplinares como arquitetura, engenharia, militares, aviação, entre outras, trabalhando ainda a diferentes escalas de projeto [14], espera-se também que os arquitetos paisagistas se adaptem aos novos métodos de trabalho, o que acarreta manterem-se atualizados, adquirirem novas competências, compreenderem e aplicarem a seu proveito os pontos fortes das novas técnicas de que é exemplo o BIM [8], [15]. Só um esforço conjunto entre profissionais de arquitetura paisagista e programadores pode conduzir à superação das atuais dificuldades.

Mesmo com os atuais obstáculos, as ferramentas BIM são poderosas e favorecem já a arquitetura paisagista [7]. Tarefas de desenho que antes tomavam tempo considerável aos gabinetes de arquitetura paisagista podem com o BIM ser agilizadas. Porém, também a grande quantidade de informação e complexidade gerada pelo BIM clama agora por novos profissionais, de que é exemplo o "BIM Manager", para gerir convenientemente essa informação [2], [16], bem como a atualização dos profissionais já existentes. Uma vez que os gabinetes de arquitetura paisagista em Portugal são em geral de pequena e média dimensão, nem sempre terão disponibilidade financeira para contratar um "BIM Manager", pelo que é imperativo que cada elemento desses gabinetes esteja comprometido em aprender e implementar o BIM [2], [16]. 


\section{Conclusões}

A falta de ferramentas especializadas para a arquitetura paisagista de modo geral nas diferentes soluções BIM continua a ser uma das principais razões apontadas por estudantes e profissionais para não utilizarem este tipo de software. Apesar disso e mesmo com essas limitações, o BIM propicia já à profissão diversas vantagens [2], [3], [8], [12], pelo que é também importante abrir mentalidades e procurar soluções que permitam desenvolver o trabalho neste tipo de software, aproximando assim a profissão dos restantes profissionais da AEC. Este trabalho retrata situações e soluções adotadas por arquitetos paisagistas, estudantes e profissionais, que procuram desenvolver o seu trabalho em BIM, mencionando ferramentas e aspetos que podem ser interessantes para os programadores, mas também para profissionais que se pretendem iniciar no BIM.

A falta de ferramentas de análise justifica que os arquitetos paisagistas continuem a usar outros tipos de software para o efeito. Porém, a troca de informação entre software de diferentes tipologias propicia a inserção de erros no trabalho, bem como um maior custo dos ateliers com o software. Apesar de a maioria dos programas BIM possuírem carência de ferramentas para a modelação de terreno, a sua contribuição para a arquitetura paisagista é, porém, promissora.

Verifica-se ainda ser importante os pavimentos exteriores possuírem interligação com o terreno e se adaptarem à sua superfície.

Enquanto que para a criação de árvores e arbustos isolados existem ferramentas próprias, verifica-se a inexistência de ferramentas especializadas para a inserção de plantas de revestimento de solo e outros conjuntos/composições de vegetação. Verifica-se ainda a necessidade de introduzir "de raiz" nos programas BIM campos associados à vegetação como nome comum, nome científico, cultivar, sazonalidade, perímetro à altura do peito, altura, entre outros [5], tendo na generalidade das soluções BIM, os arquitetos paisagistas de criar vegetação com "templates" muitas vezes vocacionados para materiais inertes.

Sendo os programas BIM ferramentas cada vez mais fundamentais ao trabalho do arquiteto paisagista, a sua adoção generalizada, aliada às capacidades $8 \mathrm{D}$ e a toda a informação contida no modelo, permitirá aos arquitetos paisagistas tomar decisões mais informadas, realizar simulações e impulsionar a profissão para o futuro.

\section{Referências}

[1] N. O. Nawari, Building Information Modeling Automated Code Checking and Compliance Processes, CRC Press, 2018.

[2] A. Nessel, "The Place for Information Models in Landscape Architecture, or a Place for Landscape Architects in Information Models," Peer Reviewed Proceedings of Digital Landscape Architecture 2013, pp. 65-72, 2013.

[3] A. M. Ahmad e A. A. Aliyu, "The need for landscape information modelling (LIM) in landscape architecture," in 13th Digital Landscape Architecture Conference, Germany, 2012.

[4] Y.-J. Chen, H.-Y. Kuo e C.-J. Chen, "Study on the establishment of a maintenance mode for a BIM-based landscape project," Building Information Modelling (BIM) in Design, Construction and Operations III, vol. 192, pp. 181-192, 2019. 
[5] V. Z. Zajickova e H. Achten, "Landscape Information Model: Plants as the components for information modelling," in Proceedings of the 31st eCAADe Conference, Delft, The Netherlands, 2013.

[6] R. Holland, J. Messner, K. Parfitt, U. Poerschke e M. Pihlak, "Integrated Design Courses Using BI M as the Technology Platform," The BIM-Related Academic Workshop, pp. 1$12,2010$.

[7] W. Suyu e C. Xiaogang, "The Application of Building Information Modeling (BIM) in landscape Architecture Engineering," Journal of Landscape Research, vol. 10, nº 6, p. 5, 2018.

[8] A. Mengots, "Review of digital tools for landscape architecture," Landscape Architecture and Art, vol. 8, nº 8, pp. 72-77, 2016.

[9] A. Ozimek e P. Ozimek, "The Idea of "Integrated Design" in Digital Techniques Teaching," Peer Reviewed Proceedings Digital Landscape Architecture 2012 at Anhalt University of Applied Sciences, 2012.

[10] I. Kamardeen, "8D BIM modelling tool for accident prevention through design," in Association of Researchers in Construction Management, ARCOM 2010 - Proceedings of the 26th Annual Conference, 2010.

[11]T. SILVA, R. MANTA, B. TETI, S. B. MELHADO, B. BARKOKÉBAS JUNIOR e K. LAFAYETTE, "Bim (8D) Como Ferramenta De Gestão Em Segurança Ocupacional: Perspectivas De Uso," pp. 636-646, 2019.

[12] T. Flohr, "A landscape architect's review of building information modeling technology," Landscape Journal, vol. 30, $\mathrm{n}^{\circ}$ 1, pp. 169-170, 2011.

[13] U. Poerschke, R. J. Holland, J. I. Messner e M. Pihlak, "BIM collaboration across six disciplines," in EG-ICE 2010 - 17th International Workshop on Intelligent Computing in Engineering, 2019.

[14] M. Pietsch, M. Heins, E. Buhmann e C. Schultze, Object-based, Process-oriented, Conceptual Landscape Models - A Chance for Standardizing Landscape Planning Procedures in the Context of Road Planning Projects, DLA 2009, Proc. of Digital Landscape Architecture, 2009.

[15] R. Holland, S. Wing e D. Goldberg, "Interdisciplinary collaborative BIM studio," in BIM Academic Symposium, 2013.

[16] J. L. Sipes, Integrating BIM Technology into Landscape Architecture, American Society of Landscape Architects, 2008. 